\title{
Immunocytochemical indicators of apoptosis in gingival tissues of patients with chronic periodontitis
}

\author{
Aldona Kasprzak', Miłosz Hausmann', Agata Małkowska-Lanzafame², \\ Joanna Surdyk-Zasada', Wiesława Przybyszewska', Elżbieta Siodła', Anna Surdacka² \\ ${ }^{1}$ Chair and Department of Histology and Embryology \\ ${ }^{2}$ Department and Clinics of Conservative Dentistry and Periodontology, Poznan University of Medical Sciences, Poland
}

\begin{abstract}
Introduction. Inflammatory mechanisms of chronic periodontitis (CP) may be linked to various forms of disturbances in apoptosis.

Aim. The study aimed at comparison of tissue expression of anti-apoptotic protein ( $\mathrm{Bcl}-2)$ and proapoptotic proteins ( $\mathrm{p} 53$, caspase-3) in gingival tissues of 30 patients with $\mathrm{CP}$ and of 15 with healthy periodontium.

Material and methods. Gingival samples $(n=68)$ were obtained during the open curettage procedure with gingivectomy of adult patients (18 women and 12 men) with CP. Classical immunocytochemical (IHC) method was used to detect apoptotic proteins, and the obtained expression was evaluated using semi-quantitative IRS scale.

Results. No differences could be revealed in expression intensity or reciprocal correlations between apoptotic proteins within the group of patients with CP. Greater expression of the two apoptotic proteins (Bcl-2 and p53) were detected in patients with CP than in control individuals. Moreover, a more pronounced expression of $\mathrm{BCl}-2$ was demonstrated in gingival samples of patients with localised form as compared to generalised form of CP. Expression of caspase-3 (effector phase of apoptosis) manifested no differences between CP and control individuals. Greater expression of the anti-apoptotic protein Bcl-2 and caspase-3 was detected in cells of inflammatory infiltrates in lamina propria than in keratinocytes.

Conclusions. In CP significant alterations developed in expression of indicators of apoptosis, with prevalence of $\mathrm{BCl}-2$ and p53 expression, as compared to the control. The localised form of CP was linked to higher proportion of $\mathrm{BCl}$-2-positive cells of inflammatory infiltrates, suggesting that apoptosis was inhibited mainly in this form of CP. The comparable expression of caspase- 3 in gingival cells with CP and in control and absence of correlation with clinical data suggested that the process of apoptosis did not play a significant role in destruction of periodontium tissues in CP.
\end{abstract}

Key words: chronic periodontitis, apoptosis, immunocytochemistry.

\section{Introduction}

Chronic periodontitis (CP) develops due to bacterial and/or viral infection and is accompanied by a progressive loss of clinical attachment level/loss (CAL) and of alveolar bone. The process represents one of principal causes of dental loss in adult patients [1-3]. It is estimated that in various world populations $1-5 \%$ individuals suffer from aggressive periodontitis and
$80 \%$ from chronic periodontitis, which allows to consider CP as representing a social problem [4]. Several hypotheses exist related to pathomechanisms of the disease [3-5]. Involvement of bacteria which are pathogenic for periodontal tissues (A. actinomycetemcomitans, Porphyromonas gingivalis, Prevotella intermedia, Tannarella forsythensis) in promotion of cell apoptosis was confirmed by numerous studies in the in 
vitro models and in the in vivo conditions [6-12]. The most typical for apoptosis morphological lesions in cell nuclei (increased fragmentation of DNA, the typical DNA "ladder") were induced by Tannarella forsythensis (earlier termed $B$. forsythus) and serotype "a" of $A$. Actinomycetemcomitans [6]. Porphyromonas gingivalis induced a direct cytopathic effect [13, 14]. Apoptosis induced by infection with the bacteria was demonstrated in several cell types, i.e. in peripheral blood mononuclear cells (PBMCs) [13], lymphocytes [14], epithelial cells $[9,11,12]$, fibroblasts and endothelial cells of gingival blood vessels [15-18] and in macrophages $[6,12]$. The in vitro models explained role of bacterial factors engaged in the apoptotic process in periodontitis. A proportion of authors indicated that gingipains (Arg-gingipain, and Lys-gingipain) and endopeptidase $\mathrm{O}(\mathrm{PepO})$ may induce alterations in adhesion proteins and may promote apoptosis of fibroblasts and vascular endothelial cells [15-17]. A team of polish investigators demonstrated that gingipains influenced the immune system inducing degradation of TNF- $\alpha$, which resulted in, i.a., dysregulation of cytokine network and inhibition of activity manifested by transcription factor, NF-kB [19]. Other investigators showed that apoptosis in primary human gingival fibroblasts (HGF) in infection with $P$. gingivalis developed in two stages and involved a variable in time regulation of anti- and proapoptotic molecules [18]. The authors confirmed the earlier observations that gingipains may directly promote apoptosis through the intracellular proteolytic activation of caspases.

Other studies related to the role of apoptosis in periodontitis posed the question related to the role played by inhibition of apoptotic process in chronic transformation of pathology in CP. According to certain authors, the inhibition of apoptosis in, e.g., macrophages may reflect a decreased production of interleukin 4 (IL-4) by cells of inflammatory infiltrates [20]. Other authors described the phenomenon of resistance to apoptosis manifested by infiltrating lymphocytes (absence of an appropriate expression of Fas ligand at the cell surface with preserved function of Fas receptor) [21]. Subsequent studies demonstrated induction of the anti-apoptotic $\mathrm{BCl}-2$ protein in gingival keratinocytes under effect of $P$. gingivalis [22]. Yilmaz et al. provided the observation that $P$. gingivalis at first triggered surface phosphatidylserine exposure through a mechanism requiring caspase activation, but after 1 day of infection protected infected cells against apoptosis [23].

Using immunocytochemical (IHC) techniques apoptotic proteins in CP were demonstrated both in epitheli- al keratinocytes and in cells of inflammatory infiltrates in lamina propria [8-10, 14, 24]. A more pronounced expression of proapoptotic proteins was manifested in gingival samples of $\mathrm{CP}$ patients than in a control group $[8,14]$. Studies related to the active phase of apoptosis suggested that activation of caspases $(-3,-7$ and PARP) represents the principal trait of tissue injury in the course of periodontitis and it affects both keratinocytes and connective tissue cells [10].

This study aimed at comparison of expression manifested by key apoptotic proteins, i.e., the anti-apoptotic $\mathrm{BCl}-2$ protein and the two pro-apoptotic proteins, p53 (early phase of apoptosis) and caspase-3 (effector phase of apoptosis) in gingival samples obtained from patients with $\mathrm{CP}$ and from persons with clinically healthy periodontium, as related to selected clinical data.

\section{Material and methods}

Clinical data of CP patients and of control individuals are given in Tables 1 and 2 . The studies were conducted on the total of 17 patients with generalised form of CP and 13 patients with localised CP. The parameter defining clinical advancement of the disease involved clinical attachment level/loss (CAL), estimated using Florida Probe ${ }^{\circledR}$. The system consists of a periodontological optical probe PD/CEJ and a computer software FP32 v.6. The PD/CEJ (10.8×0.45 mm STANDARD probe) manifests the accuracy of $0.2 \mathrm{~mm}$ at the pressure corresponding to weight of $15 \mathrm{~g}$. The values of CAL I, II and III were demonstrated in, respectively, 7, 19 and 42 fragments of gingivae obtained from CP patients (Table 1).

\section{Tissue material}

Gingival samples $(n=68)$ from 30 adult patients (18 women and 12 men; mean age: $45 \pm 2$ years) were isolated using a scalpel from various sextants, from proximity of various maxillary and mandibular teeth (mainly incisors, canines and premolars) during the open curretage with gingivectomy, following a successful completion of hygienic phase of the periodontal therapy (API index <15\%) (Table 1). In every patient 1-4 fragments of periodontal tissues were sampled from proximity of various teeth with various values of CAL: CAL I $\leqslant 3 \mathrm{~mm}$, CAL II 4-6 mm, CAL III $\geqslant 7 \mathrm{~mm}$. The control material (negative control) included gingival samples isolated from 15 patients with clinically healthy periodontium, the gingival fragments of which were sampled during procedures of esthetic periosur- 
Table 1. Selected clinical data on patients with chronic periodontitis (CP) and semiquantitative evaluation of tissue expression of apoptotic proteins (Bcl-2, p53, caspase-3) in gingival samples

\begin{tabular}{|c|c|c|c|c|c|c|c|c|}
\hline Patient & Age (years); sex & CP form & Proximity of tooth no. & CAL & Grading & $\mathrm{BCl}-2^{*}$ & p53* & caspase $-3^{*}$ \\
\hline \multirow{3}{*}{1.} & \multirow{3}{*}{$47 ; M$} & \multirow{3}{*}{ G } & 21 & III & 3 & $0 / 6$ & $\mathrm{nt}$ & $0 / 3$ \\
\hline & & & 11 & III & 3 & $0 / 6$ & $\mathrm{nt}$ & $0 / 3$ \\
\hline & & & 12 & III & 3 & $0 / 9$ & $6 / 3$ & $0 / 6$ \\
\hline \multirow{3}{*}{2.} & \multirow{3}{*}{$52 ; F$} & \multirow{3}{*}{$\mathrm{L}$} & 33 & I & 2 & $\mathrm{nt}$ & nt & nt \\
\hline & & & 31 & III & 1 & $0 / 6$ & $4 / 3$ & $3 / 3$ \\
\hline & & & 41 & III & 1 & $\mathrm{nt}$ & $6 / 6$ & $6 / 9$ \\
\hline \multirow{6}{*}{3.} & \multirow{6}{*}{$47 ; M$} & \multirow{6}{*}{ G } & 22 & $\|$ & 3 & $0 / 3$ & nt & $0 / 9$ \\
\hline & & & 11 & III & 3 & $0 / 3$ & $0 / 2$ & $0 / 6$ \\
\hline & & & 14 & III & 2 & $0 / 4$ & nt & $0 / 3$ \\
\hline & & & 33 & III & 3 & $0 / 3$ & $6 / 2$ & $0 / 3$ \\
\hline & & & 41 & III & 3 & $3 / 4$ & $6 / 0$ & $0 / 9$ \\
\hline & & & 43 & III & 3 & $0 / 12$ & $0 / 3$ & $2 / 4$ \\
\hline \multirow{4}{*}{4.} & \multirow{4}{*}{$49 ; \mathrm{F}$} & \multirow{4}{*}{ G } & 42 & $\|$ & 1 & $0 / 0$ & nt & $\mathrm{nt}$ \\
\hline & & & 32 & III & 3 & $0 / 6$ & $\mathrm{nt}$ & $0 / 3$ \\
\hline & & & 31 & III & 3 & $0 / 8$ & $3 / 3$ & $0 / 3$ \\
\hline & & & 41 & III & 2 & $\mathrm{nt}$ & $0 / 0$ & $0 / 2$ \\
\hline \multirow{3}{*}{5.} & \multirow{3}{*}{$20 ; \mathrm{F}$} & \multirow{3}{*}{ L } & 22 & 1 & 2 & $6 / 8$ & $0 / 3$ & $0 / 6$ \\
\hline & & & 11 & II & 2 & $0 / 2$ & nt & $0 / 0$ \\
\hline & & & 13 & $\|$ & 2 & $3 / 3$ & $3 / 3$ & $0 / 0$ \\
\hline \multirow{3}{*}{6.} & \multirow{3}{*}{ 49; M } & \multirow{3}{*}{ L } & 31 & III & 3 & $2 / 6$ & $6 / 3$ & $2 / 2$ \\
\hline & & & 33 & 1 & 3 & $0 / 4$ & $6 / 4$ & $0 / 3$ \\
\hline & & & 41 & III & 3 & $0 / 6$ & $6 / 0$ & $0 / 9$ \\
\hline \multirow{4}{*}{7.} & & & 44 & 1 & 2 & $4 / 0$ & $0 / 3$ & $0 / 9$ \\
\hline & $63 . \mathrm{F}$ & G & 43 & III & 3 & $0 / 9$ & $0 / 3$ & $0 / 3$ \\
\hline & $63 ; \mathrm{F}$ & G & 42 & III & 2 & $0 / 0$ & $3 / 0$ & $6 / 6$ \\
\hline & & & 33 & III & 2 & $0 / 0$ & $0 / 3$ & $0 / 8$ \\
\hline 8. & $28 ; \mathrm{F}$ & $\mathrm{L}$ & 37 & $\|$ & 1 & $0 / 8$ & $0 / 0$ & $0 / 3$ \\
\hline & & & 41 & 1 & 2 & $0 / 4$ & $0 / 3$ & $0 / 0$ \\
\hline 9. & $58 ; F$ & G & 43 & III & 3 & $0 / 4$ & $6 / 6$ & $0 / 8$ \\
\hline & & & 45 & $\|$ & 2 & $0 / 0$ & $3 / 3$ & $0 / 2$ \\
\hline 10. & $49 ; \mathrm{F}$ & $G$ & 14 & III & 3 & $0 / 3$ & $\mathrm{nt}$ & $0 / 9$ \\
\hline 11 & $31 . \mathrm{M}$ & $c$ & 23 & $\|$ & 2 & $0 / 3$ & nt & $0 / 3$ \\
\hline 11. & $31 ; \mathrm{Tl}$ & G & 24 & $\|$ & 1 & $0 / 3$ & $6 / 3$ & $0 / 6$ \\
\hline & & & 22 & III & 2 & $6 / 0$ & $4 / 3$ & $0 / 0$ \\
\hline 12. & $47 ; M$ & G & 11 & III & 3 & $0 / 6$ & $6 / 6$ & $0 / 6$ \\
\hline & & & 12 & III & 3 & $0 / 0$ & $0 / 3$ & $6 / 6$ \\
\hline 13. & $53 ; \mathrm{F}$ & $G$ & 22 & III & 3 & $0 / 3$ & nt & $0 / 6$ \\
\hline 14 & 5.. & $c$ & 13 & III & 3 & $0 / 3$ & $8 / 8$ & $0 / 3$ \\
\hline 14. & $54 ; r$ & $G$ & 14 & III & 3 & $0 / 9$ & $0 / 3$ & $0 / 6$ \\
\hline & & & 21 & III & 2 & $0 / 6$ & $\mathrm{nt}$ & $0 / 3$ \\
\hline 15. & 56; M & G & 11 & III & 2 & $0 / 3$ & $0 / 3$ & $0 / 3$ \\
\hline & & & 23 & $\|$ & 1 & $0 / 3$ & $3 / 0$ & $0 / 3$ \\
\hline 16. & $43 ; \mathrm{F}$ & $\mathrm{L}$ & 17 & II & 3 & $0 / 4$ & $4 / 0$ & $\mathrm{nt}$ \\
\hline & & & 33 & $\|$ & 3 & $0 / 8$ & $3 / 0$ & $0 / 2$ \\
\hline 17. & $32 ; M$ & $\mathrm{~L}$ & 41 & $\|$ & 3 & $0 / 2$ & $0 / 2$ & $0 / 0$ \\
\hline & & & 42 & $\|$ & 3 & $0 / 12$ & $6 / 6$ & $0 / 0$ \\
\hline & & & 21 & $\|$ & 2 & $0 / 3$ & $\mathrm{nt}$ & $0 / 6$ \\
\hline 18. & $43 ; \mathrm{F}$ & G & 27 & III & 3 & $0 / 6$ & $6 / 3$ & $0 / 3$ \\
\hline & & & 25 & III & 3 & $0 / 6$ & $\mathrm{nt}$ & $0 / 8$ \\
\hline 19. & $59 ; \mathrm{F}$ & L & 17 & $\|$ & 2 & $0 / 4$ & $4 / 0$ & $0 / 3$ \\
\hline
\end{tabular}


Table 1 cont.

\begin{tabular}{|c|c|c|c|c|c|c|c|c|}
\hline Patient & Age (years); sex & CP form & Proximity of tooth no. & CAL & Grading & $\mathrm{BCl}-2^{*}$ & p53* & caspase- $3^{*}$ \\
\hline \multirow{3}{*}{20.} & \multirow{3}{*}{$43 ; M$} & \multirow{3}{*}{ L } & 11 & III & 3 & $0 / 9$ & $0 / 9$ & $0 / 12$ \\
\hline & & & 15 & III & 3 & nt & $6 / 0$ & $0 / 3$ \\
\hline & & & 23 & 1 & 2 & $0 / 4$ & $6 / 3$ & $0 / 3$ \\
\hline \multirow{2}{*}{21.} & \multirow{2}{*}{$29 ; \mathrm{M}$} & \multirow{2}{*}{ L } & 32 & $\|$ & 2 & $0 / 6$ & $0 / 0$ & $0 / 6$ \\
\hline & & & 42 & II & 3 & $0 / 9$ & $\mathrm{nt}$ & $0 / 3$ \\
\hline \multirow{2}{*}{22.} & \multirow{2}{*}{$47 ; \mathrm{F}$} & \multirow{2}{*}{$G$} & 31 & III & 2 & $0 / 0$ & $\mathrm{nt}$ & $0 / 0$ \\
\hline & & & 41 & III & 3 & $0 / 0$ & $0 / 2$ & $0 / 0$ \\
\hline \multirow{2}{*}{23.} & \multirow{2}{*}{$39 ; F$} & \multirow{2}{*}{ L } & 31 & II & 3 & $0 / 3$ & nt & $0 / 3$ \\
\hline & & & 42 & III & 2 & $0 / 12$ & $2 / 0$ & $0 / 0$ \\
\hline 24. & $50 ; F$ & G & 13 & III & 2 & $0 / 0$ & $6 / 3$ & $0 / 3$ \\
\hline \multirow{2}{*}{25.} & \multirow{2}{*}{$53 ; F$} & \multirow{2}{*}{ L } & 31 & III & 3 & $0 / 0$ & $0 / 3$ & $6 / 3$ \\
\hline & & & 41 & III & 2 & $0 / 6$ & $0 / 3$ & $0 / 2$ \\
\hline 26. & 51; M & $G$ & 16 & 1 & 1 & $0 / 4$ & $0 / 3$ & $0 / 3$ \\
\hline \multirow{2}{*}{27.} & \multirow{2}{*}{$28 ; M$} & \multirow{2}{*}{$\mathrm{L}$} & 21 & III & 3 & $0 / 6$ & $0 / 2$ & $0 / 9$ \\
\hline & & & 12 & III & 3 & $0 / 8$ & $\mathrm{nt}$ & $9 / 0$ \\
\hline 28. & $21 ; \mathrm{F}$ & $\mathrm{L}$ & 13 & II & 2 & $3 / 4$ & $4 / 0$ & $0 / 6$ \\
\hline 29. & $58 ; M$ & $G$ & 31 & III & 0 & $0 / 0$ & $\mathrm{nt}$ & $0 / 3$ \\
\hline 30. & $56 ; F$ & $G$ & 15 & III & 3 & $0 / 12$ & $3 / 3$ & $0 / 2$ \\
\hline
\end{tabular}

F-Female; $M$ - male; $G$ - generalised type of $C P ; L$ - localized type of $C P ; n t$ - not tested; * - expression of apoptosis proteins in 12 point semi-quantitative IRS scale (see Material and Methods); the first number indicates intraepithelial localisation, the second in lamina propria ; CAL - clinical attachment level/loss

gery, uncovering of the retained teeth and/or dental extraction. The tissue material related to the studied group (CP) and control group with respective clinical data was obtained from the Private Dental Practice in Ostrów Wlkp (MH). Written informed consent was obtained from every patient before gingivectomy,

Table 2. Semiquantitative analysis of tissue expression of apoptosis protein in control group

\begin{tabular}{cccc}
\hline Patient/age (years), sex & $\mathrm{BCl}^{*}{ }^{*}$ & $\mathrm{p53}^{*}$ & Caspase-3* $^{*}$ \\
\hline $1.29 ; \mathrm{F}$ & $0 / 0$ & $0 / 0$ & $0 / 0$ \\
\hline $2.15 ; \mathrm{M}$ & $0 / 0$ & $3 / 0$ & $6 / 0$ \\
\hline $3.24 ; \mathrm{F}$ & $0 / 3$ & $3 / 3$ & $9 / 0$ \\
\hline $4.65 ; \mathrm{M}$ & $0 / 6$ & $0 / 0$ & $2 / 0$ \\
\hline $5.45 ; \mathrm{F}$ & $0 / 0$ & $4 / 2$ & $9 / 0$ \\
\hline $6.36 ; \mathrm{M}$ & $0 / 4$ & $0 / 0$ & $3 / 0$ \\
\hline $7.25 ; \mathrm{F}$ & $0 / 0$ & $2 / 2$ & $0 / 6$ \\
\hline $8.36 ; \mathrm{F}$ & $0 / 0$ & $0 / 0$ & $3 / 0$ \\
\hline $9.24 ; \mathrm{F}$ & $2 / 0$ & $0 / 2$ & $\mathrm{nt}$ \\
\hline $10.21 ; \mathrm{F}$ & $0 / 3$ & $3 / 3$ & $6 / 8$ \\
\hline $11.29 ; \mathrm{F}$ & $0 / 3$ & $6 / 6$ & $6 / 6$ \\
\hline $12.28 ; \mathrm{M}$ & $0 / 3$ & $3 / 3$ & $6 / 0$ \\
\hline $13.23 ; \mathrm{F}$ & $0 / 3$ & $6 / 2$ & $3 / 0$ \\
\hline $14.16 ; \mathrm{M}$ & $0 / 3$ & $0 / 2$ & $3 / 0$ \\
\hline $15.16 ; \mathrm{M}$ & $0 / 0$ & $\mathrm{Nt}$ & $3 / 0$ \\
\hline
\end{tabular}

$F$ - female; $M$ - male; $n t$ - not tested; * - expression of apoptosis proteins in 12 point semiquantitative IRS scale (see Material and Methods); the first number indicates intraepithelial localisation, the second in lamina propria and approval for the study was granted by the institution's Ethical Committee (no 695/05). The entire tissue material was fixed for 24 hours in $4 \%$ buffered formalin and, then, embedded in paraffin. The mean size of the tissue material was $4 \times 2 \times 2 \mathrm{~mm}$. Serial $5 \mu \mathrm{m}$ thick sections were deposited onto SuperFrost/Plus microscope glasses.

Detection and studies on cellular localisation of $\mathrm{Bcl}-2, \mathrm{p} 53$ and active caspase-3 in gingival samples took advantage of the classic ABC (streptavidin-biotinylated peroxidase complex) immunocytochemical technique with LSAB methodology (LSAB+ System HRP, Dako, Glostrup, Denmark), described earlier [25]. Mouse or rabbit anti-human monoclonal antibodies (mAbs) were employed, directed against $\mathrm{Bcl}-2$ protein (ready to use) (Dako) and p53 protein (in dilution 1:50) (Dako) and against active form of caspase-3 protein (in dilution of 1:50) (R\&D Systems). The sections were incubated with these primary mAbs at night at $4^{\circ} \mathrm{C}$, and afterwards were incubated with the LSAB+ System HRP (Dako, Glostrup, Denmark). Following deparaffination and rehydration, the preparations were additionally boiled in $10 \mathrm{mM}$ citrate buffer in a $700 \mathrm{~W}$ microwave oven for 18 min (in case of anti-Bcl-2 and anti-p53), washed in PBS and, then, subjected to the reaction according to the standard procedure. Every test was accompanied by a negative control, in which specific antibodies were supplemented by a normal serum of a respective spe- 
cies in 0.05M Tris- $\mathrm{HCl}, \mathrm{pH}^{2}$ 7.6, supplemented with $0.1 \%$ bovine serum albumin (BSA) and $15 \mathrm{mM}$ sodium azide.

The results were evaluated using semi-quantitative 12-points immunoreactive score (IRS) scale [26]. The preparations were examined under a light microscope, at 400x magnification. In each section of gingiva, five fields in epithelium and five of lamina propria were examined.

\section{Statistical analysis}

The descriptive statistics included calculation of mean, mediane values, standard deviation and standard error of the mean for quantitative traits. For qualitative variables, a distribution of patient numbers in individual categories of a trait was analysed.

Statistical analysis took advantage of the MannWhitney $\mathrm{U}$ test for nonparametric independent data and the Wilcoxon test for nonparametric dependent data. Correlations between data rows were determined employing Spearman's rank correlation index.

For comparisons of three independent samples the nonparametric Kruskal-Wallis test was used. Test for two structural indices was used to evaluate differences

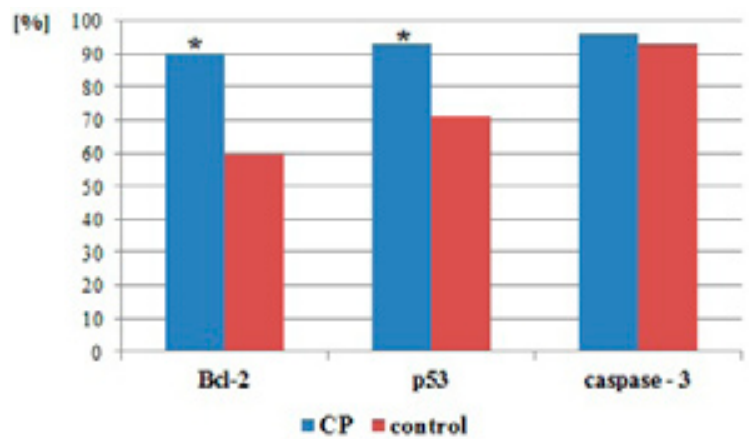

Figure 1. Comparison of detectability of apoptotic proteins (\%) in gingival samples of the patients with chronic periodontitis (CP) and in the control; ${ }^{*} p<0.05$

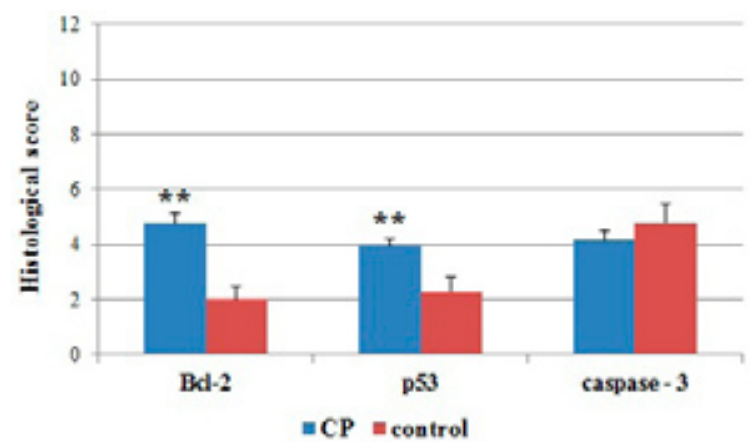

Figure 2. Comparison of tissue expression of apoptotic proteins (12-points IRS scale) in gingival samples of the patients with chronic periodontitis (CP) and in the control; ** $p<0.01$ between groups related to percentage detectability of selected traits.

Probability values less than 0.05 were considered significant.

\section{Results}

Principal clinical data and intensity of expression manifested by apoptotic proteins in gingival samples of CP patients and control individuals are presented in Tables 1 and 2. In tissue material (68 gingival fragments) of $\mathrm{CP}$ patients the highest inflammatory activity (grading 2 and 3, G2, G3) was detected in, respectively, 24 (G2) and 36 gingival fragments (G3) (Table 1).

\section{Expression of the anti-apoptotic $\mathrm{Bcl}-2$ protein} in patients with $C P$

Tissue expression of the protein was demonstrated in gingival samples of $90 \%$ patients with CP and it was significantly more pronounced than in the control (60\%) (Figure 1). In semi-quantitative evaluation of $\mathrm{BCl}-2$ expression also significantly higher amounts of the protein were detected in patients with $\mathrm{CP}$ $(4.75 \pm 0.41)$ than in the control $(2.00 \pm 0.49)$ (Fig-

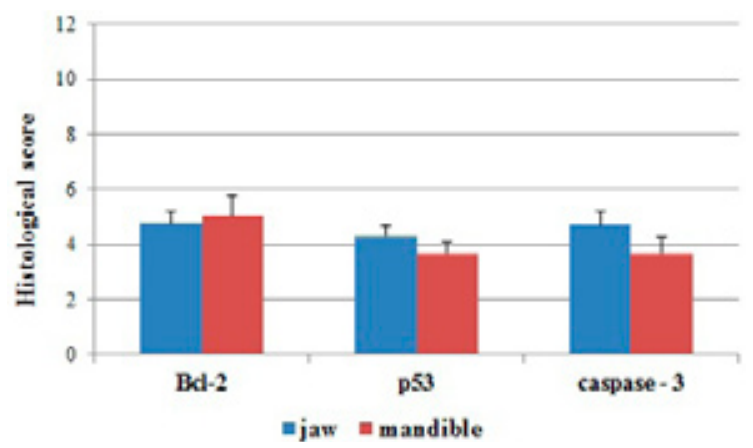

Figure 3. Comparison of tissue expression of apoptotic proteins (IRS scale) in gingival samples between maxillary and mandibular localisation of chronic periodontitis

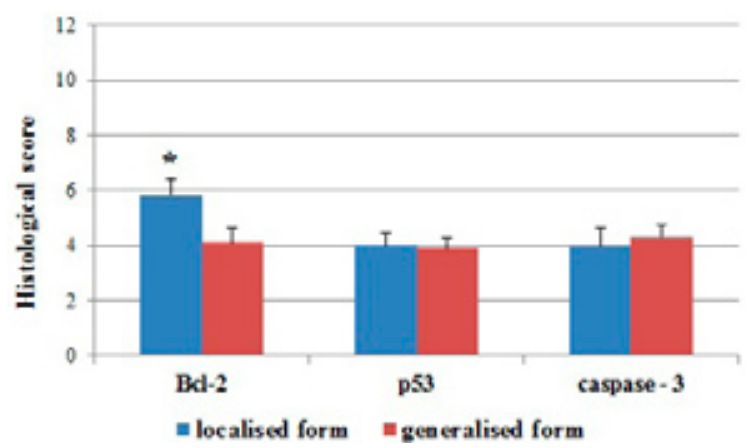

Figure 4. Comparison of tissue expression of apoptotic proteins (IRS scale) in gingival samples between localised and generalised form of chronic periodontitis 
ure 2). No quantitative differences were disclosed in $\mathrm{Bcl}-2$ expression which would be related to the location of the tooth (maxilla vs mandible) ( $4.76 \pm 0.45$ vs $5.04 \pm 0.74$ ) (Figure 3). A more pronounced expression of $\mathrm{Bcl}-2$ protein was observed in the localised form of CP $(5.83 \pm 0.62)$ than in its generalised form $(4.10 \pm 0.51)$ (Figure 4).

Product of $\mathrm{IHC}$ reaction was present mainly in perinuclear space of numerous mononuclear cells of inflammatory infiltrates (mainly lymphocytes) (Figure 5A) and, sporadically, in the cell nuclei themselves. Significantly more cells with expression of $\mathrm{Bcl}-2$ were demonstrated in cells located in lamina propria $(4.59 \pm 0.41)$ as compared to epithelial cells $(0.42 \pm 0.16)$ (Figure 6).

Analysis of proapoptotic protein expression in patients with $\mathrm{CP}$

p53 protein

The protein was detected in samples of $93 \%$ patients with $\mathrm{CP}$ and in $71 \%$ control patients, which involved a statistically significant difference (Figure 1). Semiquantitative analysis demonstrated significantly higher amounts of p53 protein in patients with
CP (3.93 \pm 0.28$)$ as compared to control patients $(2.28 \pm 0.53)$ (Figure 2). On the other hand, no significant differences in expression of the protein were detected between maxilla and mandible (4.30 \pm 0.40 and $3.67 \pm 0.43$, respectively) (Figure 3 ) or depending upon the form of the disease (localised or generalised form) $(4.00 \pm 0.47$ vs $3.89 \pm 0.35)$ (Figure 4).

p53 protein was detected in cell nuclei in cells of inflammatory infiltrate (mainly lymphocytes) and in keratinocytes of gingival epithelium and/or of periodontal pocket (Figure 5B). Individual cells of inflammatory infiltrates with cytoplasmic expression of p53 protein were found to be enlarged (macrophages, dendritic cells). No quantitative differences could be demonstrated in cellular location of the protein (lamina propria vs keratinocytes of epithelium) ( $2.59 \pm 0.30$ vs $2.88 \pm 0.38$ ) (Figure 6).

\section{Caspase-3}

Detectability of the protein in CP patients amounted to $96 \%$ and manifested no significant difference as compared to the control (93\%) (Figure 1). Surprisingly, no quantitative differences between CP patients
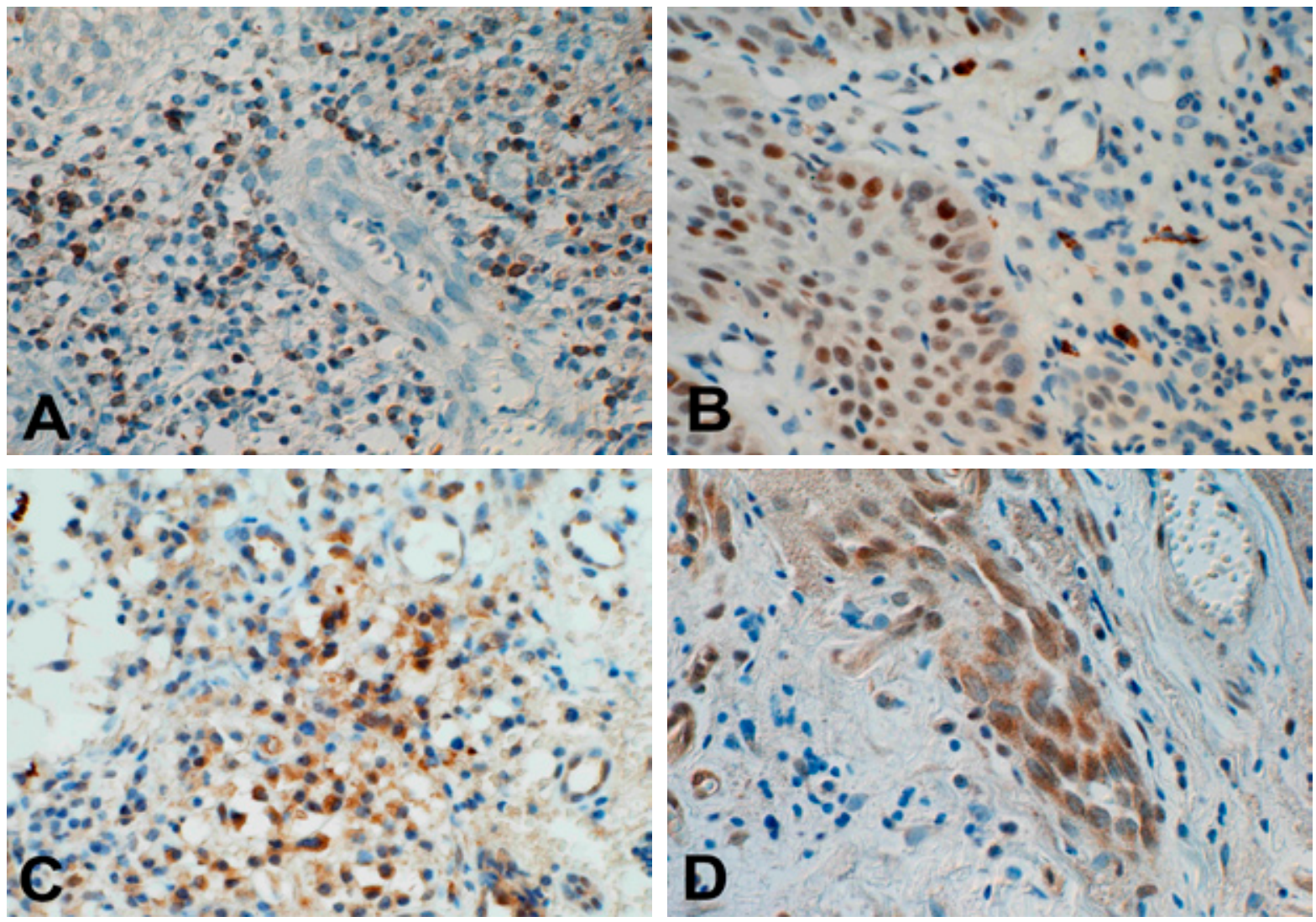

Figure 5. Immunocytochemical localisation of apoptotic proteins in gingival samples of the patients with chronic periodontitis. (A) perinuclear/nuclear localisation of Bcl-2 protein in inflammatory cells in lamina propria; (B) nuclear (in keratinocytes) and cytoplasmic (mostly in lamina propria cells) localisation of p53 protein; (C) cytoplasmic localisation of caspase-3 in inflammatory cells in lamina propria; (D) cytoplasmic localisation of caspase-3 mostly in keratinocytes of gingival sample. ABC technique. Hematoxylin counterstained. Objective magnification x40 
(4.17 \pm 0.36$)$ and the control $(4.78 \pm 0.73)$ were detected also in expression of caspase-3 (Figure 2). In contrast to expectations no significant differences in expression of the protein of effector phase of apoptosis were noted between generalised form of CP (4.30 \pm 0.42$)$ and its localised form (3.96 \pm 0.68 ) (Figure 4), nor between maxillary and mandibular localisation (4.70 \pm 0.49 and $3.68 \pm 0.58$, respectively) (Figure 3 ). As compared to epithelial keratinocytes $(0.62 \pm 0.23)$, a significantly higher expression of the protein was detected in cells of inflammatory infiltrate (mainly lymphocytes) in lamina propria (4.03 \pm 0.36$)$ (Figure 6).

Microscope examination demonstrated presence of caspase-3 in cell cytoplasm of cells in inflammatory infiltrates, epithelial cells, individual cells of vascular endothelium and fibroblasts (Figure 5C and D). Very frequently, the $\mathrm{IHC}$ reaction was very intense.

Reciprocal correlations between expression of apoptosis proteins in gingival samples of CP patients No significant relationships were detected between reciprocal expression of individual apoptosis proteins $(p>0.05)$ in patients with CP (Table 3).

\section{Reciprocal correlations between expression} of apoptosis proteins in control gingival samples In control group the only significant and direct relationship was detected between expression of two proapoptotic proteins ( $p 53$ and caspase- 3$)(r=0.547$; $p<0.05$ ) (data not shown).

Expression of apoptosis proteins in gingival samples of CP patients and selected clinical data In tissue material obtained from patients with $\mathrm{CP}$ no significant differences were detected in intensity of expression of apoptosis proteins which would depend on activity of inflammatory lesions (grading) or degree of CAL (Tables 4 and 5).

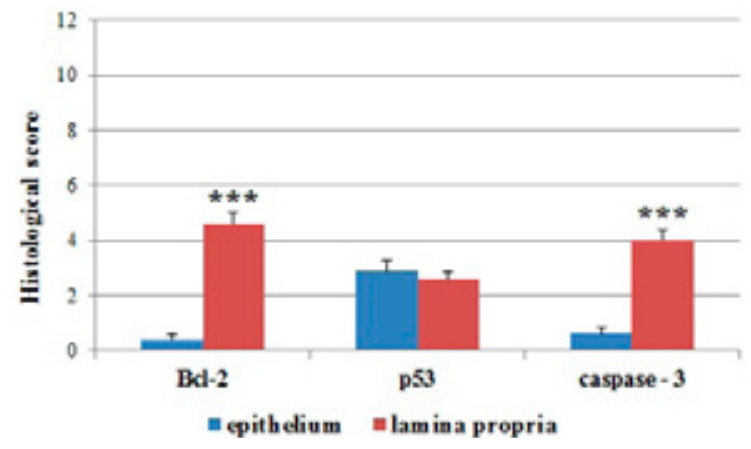

Figure 6. Comparison of tissue expression of apoptotic proteins (IRS scale) in epithelial cells and lamina propria cells in gingival samples of the CP patients; ${ }^{* *} p<0.001$
Table 3. Coefficients of Spearman's correlation between reciprocal tissue expression of apoptosis proteins within the patients with chronic periodontitis

\begin{tabular}{lcc}
\hline & $r$ & $p$ \\
\hline Expressions of $\mathrm{Bcl}-2$ and p53 & 0.012 & 0.934 \\
\hline Expressions of $\mathrm{Bcl}-2$ and caspase-3 & 0.049 & 0.705 \\
\hline Expressions of p53 and caspase- 3 & 0.216 & 0.140 \\
\hline
\end{tabular}

$r$-Spearman's correlation coefficient; $p$-level of significance

Table 4. Comparison of expression manifested by apoptosis proteins depending on intensity of inflammatory lesions (grading) in gingival tissues with chronic periodontitis (Kruskal-Wallis test)

\begin{tabular}{lc}
\hline & $p$ \\
\hline Expression of Bcl-2 and grading & 0.067 \\
\hline Expression of $\mathrm{p} 53$ and grading & 0.168 \\
\hline Expression of caspase-3 and grading & 0.229 \\
\hline$p$ - level of significance &
\end{tabular}

Table 5. Comparison of expression of apoptosis proteins depending on clinical attachment level/loss (CAL) in gingival tissues with chronic periodontitis (Kruskal-Wallis test).

\begin{tabular}{lc}
\hline & $p$ \\
\hline Expression of BCl-2 and CAL & 0.427 \\
\hline Expression of $p 53$ and CAL & 0.549 \\
\hline Expression of caspase-3 and CAL & 0.305 \\
\hline
\end{tabular}

CAL - clinical attachment level/loss; $p$ - level of significance

\section{Discussion}

$\mathrm{Bcl}-2$ is a protein of $25 \mathrm{kDa}$ molecular mass and is involved in control of cell programmed death. Expression or overexpression of the protein may protect the cell from death, preventing or delaying apoptotic process [27]. Both detectability of $\mathrm{Bcl}-2$ in patients with $\mathrm{CP}$ and its expression intensity have been significantly higher in patients with $\mathrm{CP}$ than in healthy gingival tissues, which is consistent with results obtained by other authors in case of generalised aggressive periodontitis (AP) [28]. Our studies have demonstrated slightly higher amounts of $\mathrm{Bcl}-2$ protein in the localised form of $\mathrm{CP}$ as compared to the generalised form of CP. Microscopic analysis has documented presence of $\mathrm{IHC}$ reaction product in numerous mononuclear cells of inflammatory infiltrate (mainly lymphocytes) within lamina propria. On the other hand, poor expression of the protein in lymphocytes of inflammatory infiltrate in $\mathrm{CP}$ was shown by Sawa et al. [21]. Our studies have confirmed the perinuclear location of $\mathrm{Bcl}-2$ protein [29]. In cultured human gingival fibroblasts infected with $P$. gingivalis activation of $\mathrm{Bcl}-2$ was observed in early stages of the infection (between second and 12th hour) 
[18]. Other investigations demonstrated an increase in Bcl-2 expression and inhibition of apoptosis by P. gingivalis also in cells of gingival epithelium but failed to described time-dependent alterations in expression of the protein [22]. Carvalho-Filho et al. hypothesize that $P$. gingivalis HmuY protein plays a role in the pathogenesis of $\mathrm{CP}$, possibly by reducing or delaying apoptosis in T cells through a pathway involving the $\mathrm{BCl}-2$ protein [30].

The higher expression of $\mathrm{BCl}-2$ anti-apoptotic protein detected in gingival samples (in addition in cells of lamina propria) of our patients with $\mathrm{CP}$ than in control group may suggest inhibition of apoptosis in cells of inflammatory infiltrate (mainly lymphocytes), their longer survival and, as the result, their destructive effect of periodontal tissues. However, we have failed to note significant relationships between presence of $\mathrm{BCl}-2$ and clinical indices such as grading and CAL values. Possibly, this might have reflected prevalence in the material of highly intense inflammatory lesions (grading 3) and high values of CAL parameter (CAL III) in most of the sampled fragments of gingiva with $\mathrm{CP}$. On the other hand, a significantly higher expression of $\mathrm{BCl}-2$ protein has been detected in the localised as compared to generalised form of $\mathrm{CP}$, which would suggest that the former form of CP is accompanied by a higher proportion of cells in inflammatory infiltrate with an extended life span (extended inhibition of apoptosis).

p53 protein, of $53 \mathrm{kDa}$ molecular mass, termed the genome guardian, is responsible for DNA repair and, if the lesions cannot be repaired, for induction of programmed death of the cell [31]. It leads to apoptosis of terminally differentiated cells, including cells of inflammatory infiltrate [28]. IHC techniques permit to detect only the protein of an elongated half-life (a mutated one or manifesting an increased synthesis coefficient) [31].

In this study p53 protein has been detected mostly in cell nuclei, both in cells of inflammatory infiltrate (mostly lymphocytes) and in keratinocytes. Detection of the protein both in the tissue material from patients with $\mathrm{CP}$ and in the control may point to activation of p53 production under effect of stress factors (e.g., inflammation, permanent exposure to bacterial infection in oral cavity). The more pronounced expression of p53 in patients with CP than in control individuals may indicate potential role of the protein in initiation of apoptosis (at least in some cells of inflammatory infiltrate) or may provide proof for an augmented reparative role of cell nucleus structures (mainly DNA), injured due to chronic inflammation. Other authors could not demonstrate quantitative differences in expression of the protein between patients with aggressive periodontitis and control individuals [28]. The data of Ghosh et al. demonstrated that a proapoptotic fibronectin matrix induces the degradation of ubiquitinated p53 via proteasomes in periodontal ligament cells. The authors concluded that is may be a novel mechanism of apoptosis associated with inflammatory diseases [32]. In this study we have not been able to demonstrate a relationship between expression of p53 protein and form of the disease or remaining clinical data.

Caspases represent a family of cysteine proteases which enzymatically split various substrates contain in the cell [33]. Activation of caspase-3 starts the effector apoptosis phase, leading to a cascade of event terminated by cell death and its elimination. Detection in a tissue of cells immunopositive for the so called active caspase-3 form is thought to be a significant trait of apoptosis activation [34]. It is suggested that activation of caspases represents the main character of tissue injury in the course of periodontitis. In tissues of patients with CP activation of caspase-3, caspase-7 and splitting PARP, the caspase-3 substrate was demonstrated both in keratinocytes and in connective tissue cells [10]. According to the authors, detection of high number of cells containing active forms of caspases proves that early stages of apoptosis are detected.

In our study the cytoplasmic product of IHC reaction for caspase-3 has been detected in cytoplasm of inflammatory infiltrate cells and in epithelium of gingiva and/ or periodontal pocket. A significantly higher expression has been noted in cells of inflammatory infiltrate (mainly lymphocytes) than in keratinocytes. No differences have been detected in detectability and intensity of caspase-3 expression between tissues obtained from CP patients and control individuals, consistent with the data of Bantel et al. [10]. A similar absence of differences was demonstrated in cases of AP and control [28]. Other studies demonstrated that fibroblasts represent the principal apoptosis-affected cell population in $\mathrm{CP}$, apart from only small proportion of leukocytes. The authors suggested that apoptosis of fibroblasts represented a normal phenomenon in cases of remodelling of tissues such as periodontium and that it indicated presence of an equilibrium between fibroblast proliferation and their apoptosis [24]. The results of Lucas et al. indicated that apoptosis in periodontitis may be inhibited by elevated expression of tumor necrosis factor-related apoptosis-inducing ligand (TRAIL) decoy receptors and cleaved caspase-3 inhibitors [35]. 
In contrast to expectations, our investigations have failed to demonstrate significant differences in expression of effector phase apoptotic proteins between the localised and generalised forms of CP. Both detectability of the protein in patients with $\mathrm{CP}$ and intensity of the reaction (semiquantitative evaluation) have not significantly differed from the control. Gamonal et al. demonstrated cells with active caspase-3 and other apoptotic proteins only in patients with chronic periodontitis [8]. In their studies numerous cells in apoptosis were detected also in biopsies of gingival samples with $P D \geqslant 5 \mathrm{~mm}$ and $C A L \geqslant 3 \mathrm{~mm}$. The principal cells in apoptosis involved neutrophils even if the process affected also other cells of inflammatory infiltrate [8].

In our studies we have not been able to document significant relationships between expression of caspase-3 and clinical data. Also, no reciprocal correlations have been observed in expression of apoptosis proteins within the group of patients with CP.

Results of our investigations on apoptosis markers in gingival cells of clinically healthy periodontium (lower expression of $\mathrm{BCl}-2$ and p53, but similar expression of caspase-3 as compared to CP patients, positive correlation between the two pro-apoptotic proteins) is consistent with the suggestion that periodontium tissues, continuously exposed to low degree bacterial infections may contain cells with DNA damage and a variable expression of apoptotic proteins. Tonetti et al. examining control gingival samples demonstrated apoptotic cells in particularly high numbers in subepithelial clumps of inflammatory infiltrates and within joining epithelium [36]. The caspase-3 dependent mechanism of apoptosis in experimental periodontitis in diabetic rats inoculated with $A$. actinomycetemcomitans showed increasing the inflammatory response with enhancing apoptosis of gingival epithelial and connective tissue cells [37].

\section{Summary and conclusions}

1. In chronic periodontitis significant alterations develop in expression of immunocytochemical exponents of apoptosis, with prevalence of $\mathrm{Bcl}-2$ and p53 proteins, as compared to the control.

2. The localised but not the generalised form of $\mathrm{CP}$ is accompanied by higher proportion of $\mathrm{Bcl}-2$ positive cells of inflammatory infiltrates, which suggests inhibition of apoptosis in this form of chronic periodontitis.

3. A comparable expression of caspase-3 (effector phase of apoptosis) in samples of CP patients and in clinically healthy periodontium and absence of correlation with advancement of clinical lesions in chronic periodontitis suggests that apoptotic process plays no significant role in destruction of periodontal tissue in CP.

\section{References}

1. Seymur GJ, Gemmel E, Reinhardt RA et al. Immunopathogenesis of chronic inflammatory periodontal disease: cellular and molecular mechanisms. J Periodont Res. 1993 Nov;28(6 Pt 2):478-86.

2. Loesche WJ, Grossman NS. Periodontal disease as specific, albeit chronic, infection: diagnosis and treatment. Clin Microbiol Rev. 2001 Oct;14(4):727-52.

3. Slots J, Kamma JJ, Sugar C. The herpesvirus-Porphyromonas gingivalis-periodontitis axis. J Periodontal Res. 2003 Jun;38(3):318-23.

4. Graves DT, Jiang Y, Genco C. Periodontal disease: bacterial virulence factors, host response and impact on systemic health. Curr Opin Infect Dis. 2000 Jun;13(3):227-32.

5. Wassenaar A, Reinhardus C, Thepen $T$ et al. Cloning, characterization, and antigen specificity of T-lymphocyte subsets extracted from gingival tissue of chronic adult periodontitis patients. Infect Immun. 1995 Jun;63(6):2147-53.

6. Arakawa S, Nakajima T, Ishikura $\mathrm{H}$ et al. Novel apoptosis -inducing activity in Bacteroides forsynthus: a comparative study with three serotypes of Actinobacillus actinomycetemcomitans. Infect Immun. 2000 Aug;68(8):4611-5.

7. Berker $E$, Kantarci A, Hasturk $H$ et al. Effect of neutrophil apoptosis on monocytic cytokine response to Porphyromonas gingivalis lipopolysaccharide. J Periodontol. 2005 Jun;76(6):964-71.

8. Gamonal J. Apoptosis in chronic adult periodontitis analyzed by in situ DNA breaks, electron microscopy, and immunohistochemistry. J Periodontol. 2001 Apr;72(4):517-25.

9. Jarnbring F, Somogyi E, Dalton J et al. Quantitative assessment of apoptotic and proliferative gingival keratinocytes in oral and sulcular epithelium in patients with gingivitis and periodontitis. J Clin Periodontol. 2002 Dec;29(12):1065-71.

10. Bantel H, Beikler T, Flemmig TF et al. Caspase activation is involved in chronic periodontitis. FEBS Lett. 2005 Oct;579(25):5559-64.

11. Kato $S$, Muro $M$, Akifusa $S$ et al. Evidence of apoptosis of murine macrophages by Actinobacillus actinomycetemcomitans infection. Infect Immun. 1995 Oct;63(10):3914-19.

12. Kato S, Nakashima K, Inoue $M$ et al. Human epithelial cell death caused by Actinobacillus actinomycetemcomitans infection. J Med Microbiol. 2000 Aug;49(8):739-45.

13. Geatch DR, Harris JI, Heasman PA et al. In vitro studies of lymphocyte apoptosis induced by the periodontal pathogen Porphyromonas gingivalis. J Periodontal Res. 1999 Feb;34(2):70-8.

14. Wang PL, Shirasu S, Shinohara M et al. Induction of apoptosis in human gingival fibroblasts by a Porphyromonas gingivalis protease preparation. Arch Oral Biol. 1999 Apr;44(4):337-42. 
15. Ansai T, Yu W, Urnowey S et al. Contruction of a pepO gene-deficient mutant of Porphyromonas gingivalis: potential role of endopeptidase $O$ in the invasion of host cells. Oral Microbiol Immunol. 2003 Dec;18(6):398-400.

16. Baba A, Abe N, Kadowaki $T$ et al. Arg-gingipain is responsible for the degradation of cell adhesion molecules of human gingival fibroblasts and their death induced by Porphyromonas gingivalis. Biol Chem. 2001 May;382(5):817-24.

17. Sheets SM, Potempa J, Travis J et al. Gingipains from Porphyromonas gingivalis W83 induce Cell Adhesion Molecule cleavage and apoptosis in endothelial cells. Infect Immun. 2005 Mar;73(3):1543-52.

18. Urnowey S, Ansai T, Bitko V et al. Temporal activation of anti- and pro-apoptotic factors in human gingival fibroblasts infected with the periodontal pathogen, Porphyromonas gingivalis: potential role of bacterial proteases in host signalling. BMC Microbiol. 2006 Mar;6(1):26, DOI. 10.1186/1471-2180-6-26.

19. Mezyk-Kopec R, Bzowska M, Potemba J et al. Inactivation of membrane tumor necrosis factor alpha by gingipains from Porphyromonas gingivalis. Infect Immun. 2005 Mar;73(3):1506-14.

20. Yamamoto M, Kawabata K, Fujihashi K et al. Absence of exogenous interleukin-4-induced apoptosis of gingival macrophages may contribute to chronic inflammation in periodontal diseases. Am J Pathol. 1996 Jan;148(1):331-9.

21. Sawa $\mathrm{T}$, Nishimura $\mathrm{F}$, Ohyama $\mathrm{H}$ et al. In vitro induction of activation-induced cell death in lymphocytes from chronic periodontal lesions by exogenous Fas Ligand. Infect Immun. 1999 Mar;67(3):1450-54.

22. Nakhjiri SF, Park Y, Yilmaz O et al. Inhibition of epithelial cell apoptosis by Porphyromonas gingivalis. FEMS Microbiol Lett. 2001 Jun;200(2):145-9.

23. Yilmaz $O$, Jungas $T$, Verbeke $P$ et al. Activation of the phosphatidylinositol 3-kinase/Akt pathway contributes to survival of primary epithelial cells infected with the periodontal pathogen Porphyromonas gingivalis. Infect Immun. 2004 Jul;72(7):3743-51.

24. Koulouri O, Lappin DF, Radvar M et al. Cell division, synthetic capacity and apoptosis in periodontal lesions analysed by in situ hybridization and immunohistochemistry. J Clin Periodontol. 1999 Aug;26(8):552-9.

25. Szmyt M, Kasprzak A, Malkowski W et al. Tissue expression of $\mathrm{S} 100$ proteins in gallbladder mucosa of the patients with calculous cholecystitis. Folia Histochem Cytobiol. 2013, 51(2):1-8, DOI: 10.5603/FHC.2013.0022

26. Remmele W, Stegner HE. Recomendation for uniform definition of an immunoreactive score (IRS) for immunohistochemical estrogen receptor detection (ER-ICA) in breast cancer tissue. Pathologe. 1987 May;8(3):138-40.
27. Hockenbery DM, Zutter M, Hickey W et al. Bcl-2 protein is topographically restricted in tissues characterized by apoptotic cell death. Proc Natl Acad Sci USA. 1991 Aug;88(16):6961-65.

28. Bulut $\mathrm{S}$, Uslu H, Ozdemir BH et al. Expression of caspase-3, p53 and Bcl-2 in generalized aggressive periodontitis. Head Face Med. 2006 Jun;2:17, DOI:10.1 1186/1746160X-2-17.

29. Monaghan P, Robertson D, Amos TA et al. Ultrastructural localisation of $\mathrm{BCL}-2$ protein. J Histochem Cytochem. 1992 Dec;40(12):1819-25.

30. Carvalho-Filho PC, Trindade SC, Olczak T et al. Porphyromonas gingivalis $\mathrm{HmuY}$ stimulates expression of $\mathrm{BCl}-2$ and Fas by human CD3+ T cells. BMC Microbiol. 2013 Sep 11;13:206. DOI: 10.1186/171-2180-13-206.

31. Jacks T, Weinberg RA. Cell cycle control and its watchman. Nature. 1996 Jun;381(6584):643-4.

32. Ghosh A, Joo NE, Chen TC et al. Proapoptotic fibronectin fragment induces the degradation of ubiquitinated p53 via proteasomes in periodontal ligament cells. J Periodontal Res. 2010 Aug;45(4):481-7.

33. Fischer U, Janicke RU, Schulze-Osthoff K. Many cuts to ruin: a comprehensive update of caspase substrates. Cell Death Differ. 2003 Jan;10(1):76-100.

34. Krajewska M, Wang HG, Krajewski Z et al. Immunocytochemical analysis of in vivo patterns of expression of CPP32 (caspase-3), a cell death protease. Cancer Res. 1997 Apr;57(8):1605-13.

35. Lucas $\mathrm{H}$, Bartold PM, Dharmapatni AA et al. Inhibition of apoptosis in periodontitis. J Dent Res. 2010 Jan;89(1): 29-33.

36. Tonetti MS, Cortellini D, Lang NP. In situ detection of apoptosis at sites of chronic bacterially induced inflammation in human gingival. Infect Immun. 1998 Nov;66(11):5190-95.

37. Kang J, de Brito Bezerra B, Pacios S et al. Aggregatibacter actinomycetemcomitans infection enhances apoptosis in vivo through a caspase-3-dependent mechanism in experimental periodontitis. Infect Immun. 2012 Jun;80(6):2247-56.

Correspondence address: Aldona Kasprzak

Department of Histology and Embryology Poznan University of Medical Sciences Święcickiego 6 Street 60-781 Poznan, Poland phone: +4861 8546441

fax: +486185464 40 email: akasprza@ump.edu.pl 